\title{
Food Delivery Apps and the Negative Health Impacts for Americans
}

\author{
Janna Stephens ${ }^{1 *}$, Hailey Miller ${ }^{2}$ and Lisa Militello ${ }^{1}$ \\ ${ }^{1}$ College of Nursing, Ohio State University, Columbus, OH, United States, ${ }^{2}$ School of Nursing, Johns Hopkins University, \\ Baltimore, MD, United States
}

Keywords: smartphone, food delivery, applications, fast food, obesity

\section{INTRODUCTION}

Food delivery applications have seen a surge in growth over the past decade. Digital ordering represents half of all food delivery visits, expanding beyond traditional dinner delivery to encompass breakfast and lunch delivery (1). Digital orders, ordered via a mobile app, Internet, or text message, have grown $23 \%$ over the past 4 years representing a $\$ 26.8$ billion dollar industry (2). In most instances, digital food ordering can be done directly with a restaurant app or third party food service, which allow people to view local restaurants and menus (2). GrubHub, founded in 2004, was the first successful third-party food delivery system (3). The company rapidly grew, acquiring other online businesses and expanded into the delivery service arena. With approximately 44,000 restaurants on GrubHub's platform, food sales reported in October 2019 grossed about 1.4 billion dollars, an estimated $15 \%$ gross year-over-year increase (4). With their success came other services, like UberEats, which grew by $230 \%$ in 2017 (5). It is expected that food delivery applications will have over 44 million users in the United States in 2020 (6). While this growth has both positive and negative outcomes for restaurants, expanding their market yet costing them in fees, what does it mean for the American consumers and their health?

Roughly two-thirds of the American consumer utilizing a popular food-delivery platform,

OPEN ACCESS

Edited by:

Jean C. J. Liu,

Yale-NUS College, Singapore

Reviewed by:

Miranda Mirosa,

University of Otago, New Zealand

*Correspondence:

Janna Stephens

stephens.653@osu.edu

Specialty section: This article was submitted to Eating Behavior,

a section of the journal

Frontiers in Nutrition

Received: 18 December 2019 Accepted: 04 February 2020 Published: 20 February 2020

Citation:

Stephens J, Miller $H$ and Militello $L$ (2020) Food Delivery Apps and the Negative Health Impacts for Americans. Front. Nutr. 7:14. doi: 10.3389/fnut.2020.00014 DoorDash, reported that food delivery was their preferred way of eating dinner (7). However, what many of these individuals might not realize is that the frequency of eating food from outside of the home is positively associated with a high body mass index (8). In a study done by Zion et al. (5), it was reported that $40 \%$ of people surveyed had used a multi-restaurant food delivery application in the past 90 days. Of those using the application services, 53\% used it greater than 3 times in the past 3 months and of those, $7 \%$ had used it more than 11 times. Other data suggests that $10 \%$ of Americans use delivery services weekly and 52\% typically order food delivery for lunch (9). When considering the increasing prevalence rates for overweight and obesity in the U.S., the effects of these digital food-delivery apps could be of great concern.

Overweight and obesity is a persisting epidemic in both pediatric and adult populations, with the most recent U.S. obesity (not including overweight) prevalence rates indicating that roughly $40 \%$ and $18 \%$ of adult and children are overweight or obese, respectively (10). In particular, the prevalence rate for obesity among young adults was reported to be $35.7 \%$ in 2016 . Similarly, teens between 12-19 years of age had a reported obesity prevalence rate of $20.6 \%$ (10). These statistics are alarming considering that the majority users (63\%) of food-delivery apps are youth adults ages $19-29$ years of age (5).

It is well-established from longitudinal studies that that adolescents who have better diet quality gain less weight in adulthood compared to those with poorer diet quality (11), Due to diverse and competing food-delivery platforms, users have the potential to select healthy options when opting to use digital ordering. However, reports from the most frequently used platforms highlight that American consumers' top ordered foods include a cheeseburger and fries, pizzas, nachos, cheesecake, baby back pork rib, chicken and waffle sliders, etc., indicating that calorie-dense options are some of the most popular selections to be delivered (7). Other sources report that in 2016, pizza was the most popular takeout/delivery food, followed by Asian cuisine, sandwiches, and Italian 
cuisine (9). GrubHub noted that over $70 \%$ of users utilized their applications to order quick service or fast casual foods (12). Over the past 30 years, fast food portion sizes have increased, calories have increased, and sodium levels have increased, intensifying the potential problem these applications might pose to the ongoing obesity epidemic (8).

In addition to the frequent use in the young-adult age group, these food delivery services continue to rise in popularity across adolescent American students $(13,14)$. With up to 15 deliveries a day, school districts are reevaluating their policy and banning meal delivery services due to safety concerns $(13,14)$. A synopsis of school lunch delivery services that provide, "healthy," "fresh," “organic," or "from scratch" foods average a cost of \$4-\$8 per entrée (15). This is a dramatic increase when compared to State School Nutrition data from 2017 highlighting lunch costs ranging from $\$ 2.48$ to $\$ 2.74$ per meal (16). In order to access more elite school lunch delivery services, schools must register with the service or parents must go online to coordinate/meal plan their child's food, or food service must align with National School Lunch Program standards (15). Meaning that access to healthy food deliveries is not equal across all student groups.

\section{DISCUSSION}

While we have a basic understanding of who is using these food delivery service applications and what they are ordering, there

\section{REFERENCES}

1. NPD Group. Food Service Delivery Among Fastest Growing U.S. Restaurant Industry Trends. (2018). Available online at: https://www.npd.com/wps/ portal/npd/us/news/press-releases/2018/foodservice-delivery-in- us-postsdouble-digit-gains-over-last-five-years-with-room-to-grow/ (accessed December 17, 2019)

2. NPD Group. Deliverying Digital Convenience. (2018). Available online at: https://www.npd.com/wps/portal/npd/us/news/infographics/2018/feedingthe-growing-appetite-for-restaurant-apps/ (accessed December 17, 2019)

3. Bryson York E. Why Pizza Giants Want Customers to Click, Not Call, for Delivery. (2009). Available online at: https://adage.com/article/digital/pizzagiants-customers-click-call-delivery/136087 (accessed December 16, 2019)

4. GrubHub. Grubhub Reports Third Quarter 2019 Results. (2019). Available online at: https://investors.grubhub.com/investors/press-releases/pressrelease-details/2019/Grubhub (accessed December 17, 2019)

5. Zion A, Spangler J, Hollmann T. Food delivery apps: usage and demographicswinners, losers and laggards (2019). Available online at: https://www. zionandzion.com/research/food-delivery-apps-usage-and-demographicswinners-losers-and-laggards/

6. Marston J. Food delivery apps will have 44 million U.S. users by 2020. The Spoon. (2019, December 16).

7. DoorDash. The Dish: Our End of Year Trend Report. (2019)

8. McCrory M, Harbaugh A, Appeadu S, Roberts S. Fast-food offerings in the united states in 1986, 1991, and 2016 show large increases in food variety, portion size, dietary energy, and selected micronutrients. J Acad Nutr Diet. (2019) 119:923-33. doi: 10.1016/j.jand.2018.12.004

9. Lock S. Food Delivery Industry in the U.S. - Statistics \& Facts. (2018). https:// www.statista.com/topics/1986/food-delivery-industry-in-the-us/ (accessed December 17, 2019)

10. Hales C, Carroll M, Fryar C, Ogden C. Prevalence of obesity among adults and youth: United states, 2015-2016. NCHS Data Brief. (2017) 288:1-8.

11. Hu T, Jacobs D, Larson N, Cutler G, Laska M, Neumark-Sztainer D. Higher diet quality in adolescence and dietary improvements are related to less weight is currently no research to support how digital food ordering affects health and wellness on an individual level or from a public health perspective in the U.S. Are the most frequent users of these applications overweight or obese? If so, do these individuals have a desire to consume fewer calories and lose weight? If so, what behavior change techniques may be designed into digital ordering software to help promote health? The convenience of these applications may present a greater risk to adverse health outcomes among overweight or obese individuals, who consume more calories than their normal weight counterparts (17). Similarly, will rates of fast food consumption continue to increase among low-income individuals ages 20-39, who are known to consume a higher percentage of calories from fast food compared to those with higher income levels? (17).

These questions highlight critical gaps in the literature. We strongly advocate for unbiased additional research in this arena to objectively report on user demographics, wants, and needs in the United States. Considering the ease of digital food ordering, we also strongly advocate that digital food ordering platforms adapt ethical design to improve human situations, including health.

\section{AUTHOR CONTRIBUTIONS}

JS, LM, and HM assisted in the concept of the manuscript and the writing of all sections. gain during the transition from adolescence to adulthood. J Pediatr. (2016) 178:188-93.e3. doi: 10.1016/j.jpeds.2016.08.026

12. School Nutrition Association. School Meal Trends \& Stats. (2019). Available online at: https://schoolnutrition.org/aboutschoolmeals/ schoolmealtrendsstats/ (accessed December 17, 2019)

13. Povich ES. Students, bored by cafeteria fare, love food delivery services; schools don't. Washington Post. (2019) Available online at: https://www. washingtonpost.com/health/students-bored-by-cafeteria-fare-love-fooddelivery-services-schools-dont/2019/06/07/2568d12c-8617-11e9-98c1e945ae5db8fb_story.html

14. Wisely J. Michigan schools ban grubhub and other food deliveries during school day. Detroit Free Press. (2019). Available online at: https://www. freep.com/story/news/education/2019/04/10/schools-ban-food-deliveriesgrubhub-doordash-ubereats/3400131002/

15. Grubhub. Grubhub Releases Annual "Year in Food" Report Detailing Most Popular Dining Trends of 2018. (2018).

16. Heckscher M. 11 awesome school lunch delivery services. Red Tricycle. (2019). Available online at: http://redtri.com/awesome-and-healthy-school-lunchdelivery-services/

17. Fryar C, Ervin R. Caloric intake from fast food among adults: United states, 2007-2010. NCHS Data Brief. (2013) 114:1-8.

Conflict of Interest: The authors declare that the research was conducted in the absence of any commercial or financial relationships that could be construed as a potential conflict of interest.

Copyright (c) 2020 Stephens, Miller and Militello. This is an open-access article distributed under the terms of the Creative Commons Attribution License (CC BY). The use, distribution or reproduction in other forums is permitted, provided the original author(s) and the copyright owner(s) are credited and that the original publication in this journal is cited, in accordance with accepted academic practice. No use, distribution or reproduction is permitted which does not comply with these terms. 